\title{
Osteopontin as a Marker of Lower Extremity Arterial Disease in Type 2 Diabetic Patients in Zagazig University
}

\author{
Jehan Saeed $^{1}$, Sally Mahmoud Saeed ${ }^{2}$, Ali Irhoumah Mohamed ${ }^{* 1}$, Mohamed Gaber Hamed ${ }^{1}$ \\ Departments of ${ }^{1}$ Internal Medicine and ${ }^{2}$ Biochemistry and Molecular Biology, \\ Faculty of Medicine, Zagazig University. \\ *Corresponding author: Ali Irhoumah Mohamed, Email: alirhoma14@gmail.com
}

\begin{abstract}
Background: Diabetic individuals often have lower extremity arterial disease (LEAD), which is a prevalent symptom of macrovascular disease with both a high prevalence and significantly worse outcomes. There are numerous biological activities for osteopontin (OPN) in health and illness. Objective: This study aimed to investigate whether serum OPN levels differ between type 2 diabetic subjects with and without LEAD and to examine the differences in serum OPN levels between subjects with and without type 2 diabetes mellitus (T2DM). Patients and Methods: Zagazig University Hospitals' Departments of Internal Medicine, Endocrinology Unit, and Biochemistry Department collaborated in this case-control study. Sixty people were divided into three groups: a control group of 30 people, 15 type 2 diabetics without LEAD, and 15 type 2 diabetics who had LEAD. ELISA kits were used to measure levels of osteopontin in the blood. LEAD was assessed using ankle brachial index (ABI) measurements made with a hand Doppler.

Results: Diabetics had higher serum OPN levels than non-diabetics $(111.53 \pm 35.6 \mathrm{ng} / \mathrm{ml}, 35.91 \pm 10.50 \mathrm{ng} / \mathrm{ml})$ respectively. OPN values in diabetics with LEAD group were substantially higher $(147.35 \pm 25.59 \mathrm{ng} / \mathrm{ml})$ compared to diabetics without LEAD group $(75.70 \pm 16.96 \mathrm{ng} / \mathrm{ml})(\mathrm{p}<0.001)$. Conclusion: Individuals with type 2 diabetes mellitus and have LEAD was found to have higher levels of serum osteopontin than in diabetics without LEAD, this concludes that OPN can be a marker for vascular disease of the lower extremities in diabetic patients.
\end{abstract}

Keywords: Lower extremity arterial disease, Osteopontin, Type 2 Diabetes Mellitus.

\section{INTRODUCTION}

It is estimated that $90-95$ percent of people with diabetes have type 2 diabetes (T2D), which is a developing epidemic that's linked to a variety of health problems, including coronary artery disease, diabetic retinopathy, peripheral neuropathy, and kidney disease. This means that understanding the risk factors for type 2 diabetes will be more useful in developing T2D prevention strategies ${ }^{(\mathbf{1})}$.

Another important manifestation of atherosclerosis is a condition known as lower extremity arterial disease (LEAD), which affects an estimated 200 million people globally. The fact is that (LEAD) is a prevalent symptom of diabetes-related macrovascular disease, with a high prevalence and even worse prognosis in diabetic patients ${ }^{(2)}$.

LEAD was discovered to coexist with the microvascular consequences of diabetes mellitus, according to the previous research ${ }^{(3)}$. LEAD is typically found in diabetic patients who have poorer outcomes, such as a four- to five-fold increased risk of lower limb amputation compared to healthy controls ${ }^{(4)}$.

One of the many names for osteopontin (OPN) is "early T-lymphocyte activation," "secreted phosphoprotein 1", or "uropontin". Osteopontin was first discovered in the bone matrix as an osteoblast secretory product. Some of the tissues and cell types where it is found include the osteocyte, fibroblast and endothelium as well as vascular smooth muscle cells. It is also found in dendritic, macrophage and $\mathrm{T}$ lymphocyte cells in the immune system ${ }^{(5)}$.
OPN appears to have a wide range of biological roles in both normal and pathological states, which is not surprising given its chemical structure. It regulates bone mineralization and has a powerful effect on the prevention of ectopic calcium deposition, which includes the hardening of blood vessel walls. Inflammation, immune cell migration into tissues, and wound healing have all been linked to this protein ${ }^{(6)}$.

The study's goal was to see if serum OPN levels differed between diabetics with and without LEAD, and if they did, whether they differed between people with and without T2DM.

\section{PATIENTS AND METHODS}

Zagazig University Hospital's Internal Medicine, Endocrinology Unit, and Biochemistry Departments conducted this case-control study between January 2021 and July 2021. Three groups were formed from the participants: sixty people were divided into three groups: a control group of 30 people, 15 type 2 diabetics without LEAD, and 15 type 2 diabetics who had LEAD.

Inclusion criteria: Both sexes and those who were at least 18 years old were included in the study, and longer than five years of diabetes duration among type 2 diabetics.

Exclusion criteria: Age under 18, type 1 diabetes, diabetes duration under 5 years, pregnancy, major hepatic or cardiorespiratory disease, cancer, acute sickness, history of lower limb revascularization, foot ulceration, and acute limb ischemia are all exclusions. 
All included subjects were submitted to the following:

- Detailed medical history including age, duration of diabetes mellitus, history of other diseases or comorbidities and malignancy.

- Physical exam including pulse and blood pressure measurements as well as anthropometric data such as body mass index (BMI) and height in metres. (BMI $=$ Weight $\left.(\mathrm{Kg}) / \mathrm{Height}^{2}(\mathrm{~m})\right)$. Ankle brachial index (ABI) measurement done to assess LEAD; which is defined as $\mathrm{ABI} \leq 0.90$. Normal $\mathrm{ABI}$ values 0.91 to 1.30 .

- A laboratory experiment was carried out in the morning, following a 10 to 12-hour fast and at a constant ambient temperature. Measurements revealed that smoking and caffeine intake were restricted for 8 to 10 hours, and medications were withheld from the subjects until the end of the assessment.

Assaying the amount of human OPN in samples was carried out using an enzyme-linked immunosorbent assay (ELISA) kit that utilizes a double antibody sandwich and an enzyme-linked immunosorbent assay (ELISA) (USA).

Ethical consent:

An approval of the study was obtained from Zagazig University Academic and Ethical Committee. Every patient signed an informed written consent for acceptance of participation in the study. This work has been carried out in accordance with The Code of Ethics of the World Medical Association (Declaration of Helsinki) for studies involving humans.

\section{Statistical Analysis}

Data were gleaned from history taking, clinical examinations, and laboratory tests. In the end, the data were analysed with the help of Microsoft Excel. To conduct the study, the data were imported into SPSS 20.0 (Statistical Package for the Social Sciences). Qualitative data were represented as number and percentage, and quantitative data as mean \pm SD. ChiSquare test $\left(\mathrm{X}^{2}\right)$ was used for qualitative variable difference and association. Quantitatively independent groups were compared using $t$ tests. Pearson's correlation coefficient was also calculated. $\mathrm{P}$ value was set at 0.05 for significant outcomes and 0.001 for highly significant outcomes.

\section{RESULTS}

Diabetes group and control group were not significantly different in terms of age, sex, and smoking, but the body mass index (BMI) was significantly higher among diabetic group compared to control group (Table 1).

Table (1): Demographic data distribution between diabetic group and control group

\begin{tabular}{|c|c|c|c|c|c|c|}
\hline & $\begin{array}{l}\text { Diabetic } \\
\text { group }\end{array}$ & $\begin{array}{l}\text { Control } \\
\text { group }\end{array}$ & $t / X^{2}$ & $\mathbf{P}$ \\
\hline \multicolumn{3}{|c|}{ Age (years) } & $53.83 \pm 3.83$ & $52.60 \pm 4.21$ & 1.179 & 0.243 \\
\hline \multicolumn{3}{|c|}{ BMI $\left(\mathrm{kg} / \mathrm{m}^{2}\right)$} & $27.27 \pm 2.08$ & $26.29 \pm 1.47$ & 2.098 & $0.040 *$ \\
\hline \multirow[t]{4}{*}{ Sex } & \multirow[t]{2}{*}{ Male } & $\mathrm{N}$ & 15 & 17 & & \\
\hline & & $\%$ & $50.0 \%$ & $56.7 \%$ & & \\
\hline & \multirow[t]{2}{*}{ Female } & $\mathrm{N}$ & 15 & 13 & 0.26 & 0.605 \\
\hline & & $\%$ & $50.0 \%$ & $43.3 \%$ & & \\
\hline \multirow{4}{*}{$\begin{array}{l}\text { Smokin } \\
\mathrm{g}\end{array}$} & \multirow[t]{2}{*}{ Non } & $\mathrm{N}$ & 22 & 24 & & \\
\hline & & $\%$ & $73.3 \%$ & $80.0 \%$ & & \\
\hline & \multirow[t]{2}{*}{ Smoker } & $\mathrm{N}$ & 8 & 6 & 0.37 & 0.54 \\
\hline & & $\%$ & $26.7 \%$ & $20.0 \%$ & & \\
\hline \multirow{2}{*}{\multicolumn{2}{|c|}{ Total }} & $\mathrm{N}$ & 30 & 30 & & \\
\hline & & $\%$ & $100.0 \%$ & $100.0 \%$ & & \\
\hline
\end{tabular}

Table 2 and figure 1 shows that serum OPN levels were significantly higher among diabetic group compared to control group.

Table (2): Comparison of osteopontin level between diabetic group and control group

\begin{tabular}{|l|c|c|c|c|}
\hline & Diabetic group & Control group & $\mathbf{t}$ & $\mathbf{P}$ \\
\hline OPN $(\mathrm{ng} / \mathrm{ml})$ & $111.53 \pm 35.6$ & $35.91 \pm 10.50$ & 9.519 & $<0.01^{* *}$ \\
\hline
\end{tabular}

Table 3 shows that three was no significant difference between diabetic with LEAD group and diabetic without LEAD group as regard age, body mass index, sex and smoking. 
Table (3): Demographic data distribution between diabetic with LEAD group and diabetic without LEAD group

\begin{tabular}{|c|c|c|c|c|c|c|}
\hline & $\begin{array}{c}\text { Diabetics with } \\
\text { LEAD }\end{array}$ & $\begin{array}{c}\text { Diabetics without } \\
\text { LEAD }\end{array}$ & $t / \mathbf{X}^{2}$ & $\mathbf{P}$ \\
\hline \multicolumn{3}{|c|}{ Age (years) } & $53.40 \pm 3.83$ & $54.26 \pm 3.99$ & 0.607 & 0.549 \\
\hline \multicolumn{3}{|c|}{ BMI $\left(\mathrm{kg} / \mathrm{m}^{2}\right)$} & $27.38 \pm 1.71$ & $27.15 \pm 2.46$ & 0.294 & 0.771 \\
\hline \multirow[t]{4}{*}{ Sex } & \multirow[t]{2}{*}{ Male } & $\mathbf{N}$ & 7 & 8 & & \\
\hline & & $\%$ & $46.7 \%$ & $53.3 \%$ & & \\
\hline & \multirow[t]{2}{*}{ Female } & $\mathbf{N}$ & 8 & 7 & 0.13 & 0.71 \\
\hline & & $\%$ & $53.3 \%$ & $46.7 \%$ & & \\
\hline \multirow[t]{4}{*}{ Smoking } & \multirow[t]{2}{*}{ Non } & $\mathbf{N}$ & 12 & 10 & & \\
\hline & & $\%$ & $80.0 \%$ & $66.7 \%$ & & \\
\hline & \multirow[t]{2}{*}{ Smoker } & $\mathbf{N}$ & 3 & 5 & 0.68 & 0.40 \\
\hline & & $\%$ & $20.0 \%$ & $33.3 \%$ & & \\
\hline \multirow{2}{*}{\multicolumn{2}{|c|}{ Total }} & $\mathbf{N}$ & 15 & 15 & & \\
\hline & & $\%$ & $100.0 \%$ & $100.0 \%$ & & \\
\hline
\end{tabular}

Table 4 and figure 2 shows that serum OPN levels were significantly higher among diabetic with LEAD group compared to diabetic without LEAD group.

Table (4): Comparison of osteopontin value between diabetic with LEAD group and diabetic without LEAD group

\begin{tabular}{|l|c|c|l|l|}
\hline & Diabetics with LEAD & Diabetics without LEAD & t & P \\
\hline OPN $(\mathrm{ng} / \mathrm{ml})$ & $147.35 \pm 25.59$ & $75.70 \pm 16.96$ & 9.036 & $<0.00 I^{* *}$ \\
\hline
\end{tabular}

Table 5 shows that OPN values in diabetic patients with LEAD had significant negative correlation with ABI measurements.

Table (5): correlation between osteopontin levels and ankle brachial index measurements in diabetic with LEAD group

\begin{tabular}{|l|l|c|}
\hline \multicolumn{2}{|l|}{} & OPN levels \\
\hline \multirow{2}{*}{ ABI } & $\mathbf{r}$ & -0.703 \\
\cline { 2 - 3 } & $\mathbf{P}$ & $0.00^{* *}$ \\
\hline
\end{tabular}

\section{DISCUSSION}

In the present study, BMI was significantly higher among diabetic group $\left(27.27 \pm 2.08 \mathrm{~kg} / \mathrm{m}^{2}\right)$ compared to control group $\left(26.29 \pm 1.47 \mathrm{~kg} / \mathrm{m}^{2}\right)$. This is consistent with the results of Eleftheriadou et al. ${ }^{(5)}$, who found that patients with diabetes had higher BMI than nondiabetic group. Cai et al. ${ }^{(7)}$, found that BMI was significantly different between diabetics $(26.47 \pm 3.48$ $\left.\mathrm{kg} / \mathrm{m}^{2}\right)$ and healthy controls $\left(22.67 \pm 1.48 \mathrm{~kg} / \mathrm{m}^{2}\right)$, with a significant difference (P 0.001) between the two groups. Kim and Park ${ }^{(8)}$, demonstrated that BMI is a regularly used predictor of diabetes and high blood pressure.

The current study showed that serum OPN levels were significantly higher among diabetic group $(111.53 \pm 35 \mathrm{ng} / \mathrm{ml})$ compared to control group $(35.91 \pm 10.50 \mathrm{ng} / \mathrm{ml})$ that disagrees with Eleftheriadou et al. ${ }^{(5)}$ who found that serum OPN levels were significantly higher among control group than diabetic group, which is explained by presence of some differences in demographic characteristics of participants, many subjects among diabetic group were on treatment with statins and angiotensin converting enzyme inhibitors or angiotensin receptor blockers; medications with known OPN-lowering effects ${ }^{(9)}$. Yan et al. ${ }^{(10)}$ showed that T2DM patients had significantly higher OPN levels than control group $(\mathrm{P}<0.001)$. Gordin et al. ${ }^{(11)}$ revealed that high serum OPN values are associated with long duration of diabetes and increase in BMI with no relation was found with glycaemic control (HbA1c).

The current study showed that the age was not significantly different between diabetic with LEAD group and diabetic without LEAD group as it was (53.40 \pm 3.83 years) and ( $54.26 \pm 3.99$ years) respectively, also there was no significant difference between both groups regarding body mass index, sex and smoking, which is in agreement with the study of Abián et al. ${ }^{(12)}$ who reported that the mean age between diabetic with LEAD group and diabetic without LEAD was $(63.5 \pm 11.2$ years) and (62.6 \pm 10.9 years) respectively with no significant difference between groups, also there was no significant difference regarding BMI, sex and smoking. Cai et $\boldsymbol{a l} .{ }^{(7)}$ found that in diabetic with LEAD group, the patient age was older, and the BMI was increased compared with the control group.

The current study showed that serum OPN levels were significantly higher among diabetic with LEAD group $(147.35 \pm 25.59 \mathrm{ng} / \mathrm{ml})$ compared to serum OPN levels of diabetic without LEAD group $(75.70 \pm 16.96$ $\mathrm{ng} / \mathrm{ml})(\mathrm{p}<0.01)$. Eleftheriadou et al. ${ }^{(5)}$ according to 
their study, persons suffering from LEAD showed much greater amounts of the inflammatory protein OPN in their blood than those without LEAD. Diabetes patients with lower extremity arterial disease had considerably greater serum OPN levels than diabetic patients without lower extremity arterial disease $(\mathrm{P}<0.001)$, according to Koshikawa et al. ${ }^{(13)}$.

The current study showed that OPN values had significant negative correlation with $\mathrm{ABI}$ measurements in diabetic patients with LEAD. Eleftheriadou et al. ${ }^{(5)}$ found a link between high levels of serum OPN and severe LEAD.

\section{CONCLUSION}

Individuals with type 2 diabetes mellitus and have LEAD were found to have higher levels of serum osteopontin than in diabetics without LEAD, this concludes that OPN can be a marker for vascular disease of the lower extremities in diabetic patients.

Financial support and sponsorship: Nil.

Conflict of interest: Nil.

\section{REFERENCES}

1. Roshanzamir F, Miraghajani M, Mansourian R et al. (2018): The association between circulating fetuin-A levels and type 2 diabetes mellitus risk: Systematic review and meta-analysis of observational studies. Journal of Endocrinological Investigation, 41(1): 33-47.

2. Dinh T, Scovell S, Veves A et al. (2009): Peripheral arterial disease and diabetes: a clinical update. The International Journal of Lower Extremity Wounds, 8(2): 75-81.

3. Tziomalos K, Vasilios $\mathbf{G}$ (2015): Diabetic nephropathy: New risk factors and improvements in diagnosis. Review of Diabetic Studies, 12(1):110-18.

4. Mueller T, Hinterreiter F, Luft $C$ et al. (2014): Mortality rates and mortality predictors in patients with symptomatic peripheral artery disease stratified according to age and diabetes. Journal of Vascular Surgery, 59(5):1291-99.

5. Eleftheriadou I, Tsilingiris D, Tentolouris A et al. (2020): Association of circulating osteopontin levels with lower extremity arterial disease in subjects with type 2 diabetes mellitus: a cross-sectional observational study. The International Journal of Lower Extremity Wounds, 19(2), 180-189.

6. Scatena M, Liaw L, Cecilia M et al. (2007): A multifunctional molecule regulating chronic inflammation and vascular disease. Arterioscler Thromb Vasc Biol., 27:2302-2309.

7. Cai H, Wang P, Zhang B et al. (2020): Expression of the NEK7/NLRP3 inflammasome pathway in patients with diabetic lower extremity arterial disease. BMJ Open Diabetes Research and Care, 8(2): 1808-13.

8. Kim K, Park S (2018): Association of muscle mass and fat mass with insulin resistance and the prevalence of metabolic syndrome in Korean adults: a cross-sectional study. Sci Rep., 8(1):2703-2706.

9. Wolak T (2014): Osteopontin - A multi-modal marker and mediator in atherosclerotic vascular disease. Atherosclerosis, 236(2):327-37.

10. Yan X, Sano M, Lu L et al. (2010): Plasma concentrations of osteopontin, but not thrombin-cleaved osteopontin, are associated with the presence and severity of nephropathy and coronary artery disease in patients with type 2 diabetes mellitus. Cardiovascular Diabetology, 9(1): 1-8.

11. Gordin $D$, Thomas $N$, Bjerre $M$ et al. (2014): Osteopontin is a strong predictor of incipient diabetic nephropathy, cardiovascular disease, and all-cause mortality in patients with type 1 diabetes. Diabetes Care, 37(9): 2593-2600.

12. Abián M, Vanesa B, Diego B et al. (2021): Frequency of lower extremity artery disease in type 2 diabetic patients using pulse oximetry and the ankle-brachial index. International Journal of Medical Sciences, 18(13): 2776-81.

13. Koshikawa M, Aizawa $K$, Kasai $H$ et al. (2009): Elevated osteopontin levels in patients with peripheral arterial disease. Angiology, 60(1): 42-45. 